\title{
Upregulation of miR-96 promotes radioresistance in glioblastoma cells via targeting PDCD4
}

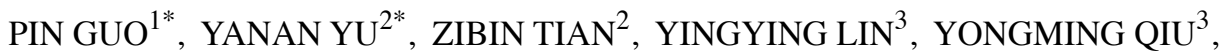 \\ WEICHENG YAO ${ }^{1}$ and LIJUAN ZHANG ${ }^{4,5}$
}

\begin{abstract}
Departments of ${ }^{1}$ Neurosurgery and ${ }^{2}$ Gastroenterology, The Affiliated Hospital of Qingdao University, Qingdao, Shandong 266003; ${ }^{3}$ Department of Neurosurgery, Renji Hospital, Shanghai Jiao Tong University School of Medicine, Shanghai 200127; ${ }^{4}$ Institute of Cerebrovascular Diseases, The Affiliated Hospital of Qingdao University; ${ }^{5}$ School of Medicine and Pharmacy, Ocean University of China, Qingdao, Shandong 266003, P.R. China
\end{abstract}

Received August 11,2017; Accepted February 2, 2018

DOI: $10.3892 / \mathrm{ijo} .2018 .4498$

\begin{abstract}
Glioblastoma multiforme (GBM) is the most deadly brain tumor, and it is characterized by extremely poor therapeutic response and overall survival. Adjuvant radiotherapy remains the standard of care following surgical resection. Thus, elucidating the mechanisms conferring radioresistance in GBM is extremely urgent. In the present study, miR-96 was demonstrated to be significantly upregulated in radioresistant GBM cells. Knockdown of miR-96 in the radioresistant GBM cells T98G elevated the \% of apoptotic cells and reduced their clonogenic formation ability following radiotherapy. By contrast, overexpression of miR-96 in the radiosensitive GBM cells U87-MG reduced the \% of apoptotic cells and increased their clonogenic formation ability following radiotherapy. Results from phosphorylated-H2A histone family member $\mathrm{X}(\gamma \mathrm{H} 2 \mathrm{AX})$ foci staining and comet assays revealed that miR-96 enhanced the DNA repair processes. Furthermore, miR-96 overexpression conferred radioresistance by downregulating programmed cell death protein 4 (PDCD4). Luciferase assay results revealed that miR-96 bound to the 3'UTR of PDCD4 mRNA. Finally, U87-MG cells regained radiosensitivity following PDCD4 overexpression. Taken together, the present is the first study to establish that upregulation of miR-96 in GBM cells confers radioresistance via targeting PDCD4, which might be a potential therapeutic target for GBM.
\end{abstract}

Correspondence to: Professor Lijuan Zhang, Institute of Cerebrovascular Diseases, The Affiliated Hospital of Qingdao University, 16 Jiangsu Road, Qingdao, Shandong 266003, P.R. China E-mail: zljneuro@163.com

Dr Weicheng Yao, Department of Neurosurgery, The Affiliated Hospital of Qingdao University, 16 Jiangsu Road, Qingdao, Shandong 266003, P.R. China

E-mail: yaoweicheng888@163.com

${ }^{*}$ Contributed equally

Key words: glioblastoma, radioresistance, miR-96, programmed cell death protein 4

\section{Introduction}

Glioblastoma multiforme (GBM) is the most frequently diagnosed and most lethal of primary brain tumors. Radiotherapy is the major approach to adjuvant therapy for patients with GBM (1). Extensive, diffuse parenchymal invasion results in the failure of surgical resection (2). It has long been recognized that GBMs are heterogeneous in their radiation response and the degree of radiosensitivity is believed to be related to intrinsic and extrinsic properties of the tumor cell population (3-5). The effects and underlying mechanisms of radioresistance have yet to be fully clarified.

The impairment of microRNA (miRNA) regulation is one of the key mechanisms in GBM pathogenesis, as well as prognosis (6-9). miR-96 was demonstrated to be overexpressed in several types of cancer (10-13), and to promote cancer progression by increasing the activity of essential molecular pathways, such as KRAS proto-oncogene (14-18). In addition, miR-96 promotes chemo- or radioresistance by downregulating reversion inducing cysteine-rich protein with kazal motifs (RECK) in esophageal cancer (19). However, the association of miR-96 with GBM and with its radioresistance properties remains unclear.

Programmed cell death protein 4 (PDCD4) was initially demonstrated to be upregulated during apoptosis, which subsequently suppresses tumorigenesis $(20,21)$. Downregulation of PDCD4 expression is closely associated with the progression of a number of tumors, including GBM (22), and other solid tumors (23-26). Furthermore, low PDCD4 expression levels correlate with poor outcomes in patients with GBM (27). The downregulation of PDCD4 in GBM is partly due to epigenetic silencing secondary to 5 'cytosine-phosphate-guanine island methylation (28). Overexpression of miR-21 has been reported to target PDCD4 mRNA for degradation $(29,30)$. Although several studies have examined PDCD4 in glioma, the detailed molecular mechanisms underlying the role of PDCD4 in GBM remain poorly understood.

In the present study, miR-96 was demonstrated to be significantly upregulated in radioresistant GBM cells. Overexpression of miR-96 in the radiosensitive GBM cells U87-MG reduced radiosensitivity, while knockdown of 
miR-96 in the radioresistant GBM cells T98G increased radiosensitivity. Further study revealed that miR-96 bound to the 3' untranslated region (3'UTR) of PDCD4 mRNA, and that PDCD4 overexpression in leads to reversion of radiosensitivity. Altogether, the present findings established that upregulation of miR-96 in GBM cells confers radioresistance partially via targeting PDCD4, which might be a potential therapeutic target.

\section{Materials and methods}

Cell culture. The human GBM cell lines U87-MG (TCHu138) (31), U251-MG (TCHu58), A172 (TCHu171) (purchased from the Type Culture Collection of the Chinese Academy of Sciences, Shanghai, China) and T98G (CRL-1690) (purchased from ATCC, Manassas, VA, USA) were cultured in Dulbecco's modified Eagle's medium (DMEM) supplemented with $10 \%$ fetal bovine serum (FBS) (both from Invitrogen; Thermo Fisher Scientific, Inc., Waltham, MA, USA) and maintained in a humidified atmosphere with $5 \%$ carbon dioxide at $37^{\circ} \mathrm{C}$. Of note, there is a misidentification issue regarding the U87-MG cells. This cell line is likely to be a bone fide human glioblastoma cell line of unknown origin (31). Although the origin of the U87-MG cell line is unknown, the U87-MG cells are most probably also a glioblastoma cell line; thus, we considered that the use of this cell line would not affect our experimental results regarding GBM.

Western blot analysis. Total proteins $(30 \mu \mathrm{g})$ which were extracted using RIPA lysis and extraction buffer (Thermo Fisher Scientific, Inc.) and quantified by BCA assay were subjected to 8-10\% SDS-polyacrylamide gel electrophoresis and transferred onto Hybond ECL membranes (GE Healthcare Life Sciences, Shanghai, China). The membranes were blocked for $1 \mathrm{~h}$ at room temperature in blocking buffer (5\% skim milk in TBS-T) and then incubated with antibodies targeting PDCD4 (1:500; cat. no. 12587-1-AP; Proteintech Group, Inc., Chicago, IL, USA) or $\beta$-actin (1:500; Abcam, Cambridge, MA, USA) overnight at $4^{\circ} \mathrm{C}$. After washing with TBS-T, the membranes were incubated with horseradish peroxidase-conjugated anti-rabbit or anti-mouse antibody (1:10,000; cat. no. AQ132P, AQ127P; Sigma-Aldrich; Merck KGaA, Darmstadt, Germany) for $2 \mathrm{~h}$ at room temperature. Immunoreactive proteins were captured by enhanced chemiluminescence (ECL) (cat. no. WBKLS0500; EMD Millipore, Billerica, MA, USA). Quantity One analysis software version 4.6.9 (Bio-Rad Laboratories, Inc., Hercules, CA, USA) was used to quantify the relative band intensities from western blot images.

Reverse transcription-quantitative polymerase chain reaction $(R T-q P C R)$. Total RNA was extracted using TRIzol reagent (Thermo Fisher Scientific, Inc.). An equal amount of total RNA was used for first-strand cDNA synthesis using oligo(dT) primer and M-MLV Reverse Transcriptase XL (Promega Corporation, Madison, WI, USA). The synthesized first-strand of cDNA $(2 \mu \mathrm{l})$ was used for each PCR. The primers used were as follows: hsa-miR-96, 5'-TTTGGCACTAGCACATTTTTGCT-3'; PDCD4, forward, 5'-CCAAAGGGAAGGTTGCTGGATAG-3' and reverse, 5'-CCACCTCCTCCACATCATA CAC-3'. SYBRGreen PCR Master Mix (Applied Biosystems; Thermo Fisher Scientific, Inc.) was used for qPCR reactions. GAPDH was used as a loading control [primer, 5'-CATGGCCTTCCGTGTTC CTA-3' (forward) and 5'-GCGGCACGTCAGATCCA-3' (reverse)]. The qPCR cycling conditions consisted of initial denaturation for $3 \mathrm{~min}$ at $95^{\circ} \mathrm{C}$, followed by 45 cycles of $95^{\circ} \mathrm{C}$ $(10 \mathrm{sec})$ for denaturation and $58^{\circ} \mathrm{C}(45 \mathrm{sec})$ for annealing/extension combined, and data were acquired at the end of the annealing/extension phase using a Roche Lightcycler 480 machine (Roche, Basel, Switzerland). Melt curve analysis was performed at the end of each run between $58-95^{\circ} \mathrm{C}$. Data were analyzed using Microsoft Excel 2013 (Microsoft Corporation, Redmond, WA, USA). The $2^{-\Delta \Delta \mathrm{Cq}}$ relative quantification method was used to analyze quantitative RT-qPCR data using the housekeeping gene GAPDH for normalization (32).

Lentiviral vector-mediated gene knockdown or overexpression. The oligo sequences for has-miR-96 overexpression were: forward, 5'-CCGCTCGAGAGAGCAGAGACAGATCCAC GAG-3' and reverse, 5'-CGGGATCCCACAGCAGCTGAGCC AGATGG-3'. The oligo sequences for has-miR-96 knockdown were: forward, 5'-GATCCGACGGCGCTAGGATCATCAA CCCAACAGCAAAAATGTGCatctTAGTGCCAAACAAGT ATTCTGGTCACAGAATACAACAGCAAAAATGTGCatct TAGTGCCAAACAAGATGATCCTAGCGCCGTCtttttTg-3' and reverse, 5'-aattcAaaaaGACGGCGCTAGGATCATCTTG TTTGGCACTAagatGCACATTTTTGCTGTTGTATTCTGT GACCAGAATACTTGTTTGGCACTAagatGCACATTTTTG CTGTTGGGTTGATGATCCTAGCGCCGTCg-3'.

Lentiviral vectors for human miR-96 overexpression or knockdown, and for PDCD4 overexpression, were constructed by Hanyin Co. (Shanghai, China). The recombinant lentivirus and the negative control (NC) lentivirus (Hanyin Co.) were prepared and titered to $10^{9}$ transfection $\mathrm{U} / \mathrm{ml}$. To obtain the stable cell line, U87-MG cells were seeded in 6-well dishes at a density of $2 \times 10^{5}$ cells/well. The cells were then infected with the same titer virus with $8 \mu \mathrm{g} / \mathrm{ml}$ polybrene on the following day. The efficiency of knockdown or overexpression was confirmed at $48 \mathrm{~h}$ post-infection using RT-qPCR. Approximately $72 \mathrm{~h}$ post-infection, the culture medium was replaced with selection medium containing $4 \mu \mathrm{g} / \mathrm{ml}$ puromycin. The cells were then cultured for at least another 14 days. The puromycin-resistant cells were amplified in medium containing $2 \mu \mathrm{g} / \mathrm{ml}$ puromycin for seven to nine days and then transferred to a medium without puromycin.

Cell apoptosis analysis. Apoptosis was determined by translocation of phosphatidylserine to the cell surface using an Annexin V-fluorescein isothiocyanate (FITC) and propidium iodide (PI) apoptosis detection kit (BD Biosciences, Franklin Lakes, NJ, USA). Cells were treated with 0 or 6 Gy radiation. Then the cells were harvested and washed twice in cold PBS, and resuspended in Annexin V-FITC and PI solution for $30 \mathrm{~min}$ in the dark. Cell apoptosis was analyzed using CellQuest Pro software version 5.1; BD Biosciences). Fluorescence was detected with an excitation wavelength of $480 \mathrm{~nm}$.

Colony formation assay. Cells were treated with 0 or $6 \mathrm{~Gy}$ radiation prior to the colony formation assay. Briefly, $1 \mathrm{ml}$ of $0.8 \%$ agar (low melting point agarose) was added to each well (6-well plate) and allowed to set as the base agar. Then, cells 
$A=N$ m $\mathrm{A}$
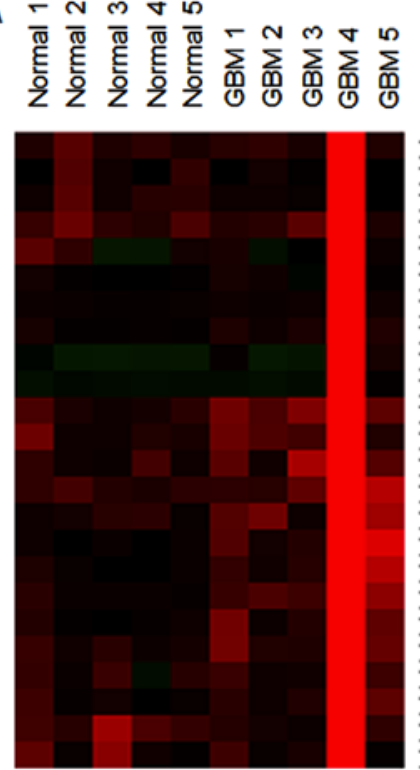

hsa-miR-302a

ha-miR-302a

hsa-miR-302b

hsa-miR-302d

hsa-miR-362-3p

hsa-miR-1251

hsa-miR-300

hsa-miR-452.

hsa-miR-548n

hsa-miR-599

hsa-miR-138-2

hsa-miR-296-5p

hsa-miR-518f

hsa-miR-200a

hsa-miR-144:9.1

hsa-miR-1265

hsa-miR-141

hsa-miR-96

hsa-miR-1537

hsa-miR-708

hsa-miR-545

hsa-miR-874

hsa-miR-33a

hsa-miR-875-5p
B

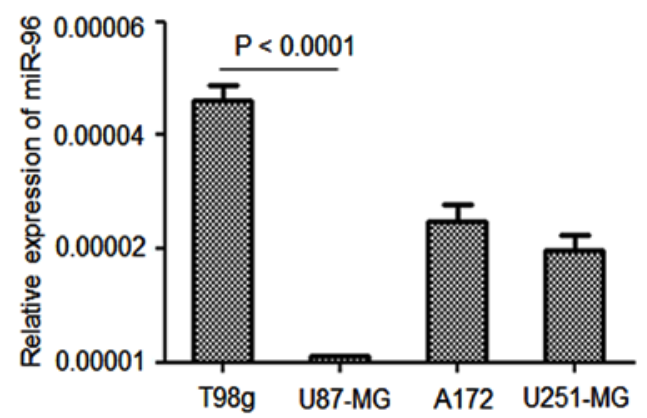

Figure 1. miR-96 is significantly upregulated in radioresistant GBM cells. (A) Heatmap of miRNA expression in normal tissues ( $\mathrm{n}=5$ ) and GBM tissues ( $\mathrm{n}=5$ ) (B) Relative miR-96 expression levels in GBM cell lines U87-MG, U251-MG, A172 and T98g. GBM, glioblastoma multiforme.

were trypsinized, and 500 cells $(0.5 \mathrm{ml})$ were seeded per well. For plating, $0.5 \mathrm{ml}$ pre-warmed DMEM with $20 \%$ FBS and $0.5 \mathrm{ml} 0.8 \%$ agar was added to tubes with cells. The mixture was gently mixed, and $1 \mathrm{ml}$ was added to each group in triplicate. The assay was incubated at $37^{\circ} \mathrm{C}$ in a humidified incubator for 10 to 14 days. Wells were stained with $1 \mathrm{ml}$ of $0.005 \%$ crystal violet for $1 \mathrm{~h}$ prior to counting colonies under a dissecting microscope.

Immunofluorescent staining of phosphorylated-H2A histone family member $X(\gamma H 2 A X)$ foci. Cells were grown and treated on chamber slides at a concentration of $10^{5}$ cells $/ \mathrm{ml}$. After incubation for $12 \mathrm{~h}$, the cells were irradiated with 0 or $6 \mathrm{~Gy}$. At the indicated time points following radiation, the cells were fixed with $2 \%$ paraformaldehyde for $15 \mathrm{~min}$ at room temperature and permeabilized with $1 \%$ Triton X-100 for 5 minon ice. The primary antibody (anti- $\gamma \mathrm{H} 2 \mathrm{AX}$; JBW301; Upstate Biotechnology, Inc., Lake Placid, NY, USA) was added at a dilution of 1:500 in $1 \%$ bovine serum albumin (BSA) and incubated for $1 \mathrm{~h}$ at room temperature. The FITC-conjugated secondary antibody (cat. no. 115-095-003; goat anti-mouse immunoglobulin G; Jackson ImmunoResearch Laboratories, Inc., West Grove, PA, USA) was added at a 1:100 dilution in 1\% BSA for $1 \mathrm{~h}$ at room temperature. The cells were treated with $1 \mu \mathrm{g} / \mathrm{ml}$ of DAPI in PBS for $30 \mathrm{~min}$ in the dark. The coverslips were mounted with anti-fade solution (VectaShield; Vector Laboratories, Inc., Burlingame, CA, USA), and the slides were examined using a fluorescent microscope (Leica Microsystems GmbH, Wetzlar, Germany). Images were captured at $\mathrm{x} 400$ magnification (5 fields were evaluated per slide per group and the average per field was calculated) and analyzed using ImageJ software (National Institutes of Health, Bethesda, MD, USA).

Comet assay. Cells grown in $100 \mathrm{~mm}^{3}$ dishes were irradiated with 0 or $6 \mathrm{~Gy}$. At the specified times, the cells were suspended at a concentration of $1 \times 10^{5}$ cells $/ \mathrm{ml}$ and combined with melted, low-melting point agarose at a 1:10 ratio and transferred onto a Comet slide (both from Trevigen, Inc., Gaithersburg, MD, USA). The slides were placed at $4^{\circ} \mathrm{C}$ for $30 \mathrm{~min}$ before being immersed in Lysis Solution (Trevigen, Inc.) for $1 \mathrm{~h}$ at $4^{\circ} \mathrm{C}$. Then, the slides were run on an horizontal electrophoresis apparatus for $10 \mathrm{~min}$ at $20 \mathrm{~V}$. PI (BD Biosciences) was added to the slides. The slides were visualized using a fluorescent microscope at x400 magnification (Leica Microsystems $\mathrm{GmbH} ; 5$ fields were evaluated per slide per group). The Olive tail moment (OTM) was recorded for each cell.

Luciferase assay. A reporter vector containing the 3'UTR of the human PDCD4 gene was cloned into the pmirGLO vector (Promega Corporation). The putative miR-96 binding elements in the 3'UTR region was mutated by site-directed mutagenesis. U87-MG or T98g cells $\left(2.5 \times 10^{5}\right.$ cells $)$ were seeded onto a 24-well dish and, the next day, were transfected with the reporter and effector constructs using the FuGENE HD transfection reagent (Roche Applied Science), according to the manufacturer's instructions. miR-96 mimics or inhibitors were transfected as well. After $48 \mathrm{~h}$, a luciferase assay was performed using the Dual-Luciferase Reporter Assay System (Promega Corporation). Normalization was carried out by comparison to Renilla luciferase activity.

Statistical analysis. Data were presented as mean \pm standard error of the mean. A Tukey test was conducted for multiple comparisons in conjunction with one way analysis of variance. All statistical analyses were performed using SPSS for Windows v.17.0 (SPSS, Inc., Chicago, IL, USA). $\mathrm{P}<0.05$ was considered to indicate a statistically significant difference.

\section{Results}

miR-96 is significantly upregulated in radioresistant GBM cells. The microarray data downloaded from NCBI (GSE25631) 


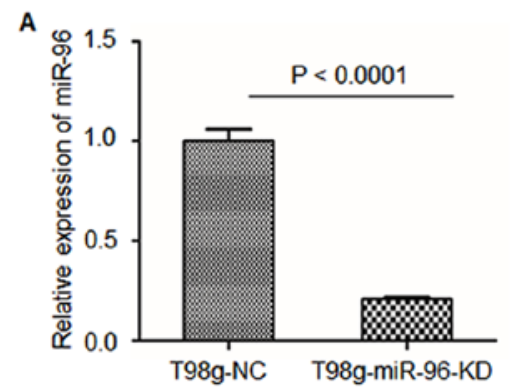

D

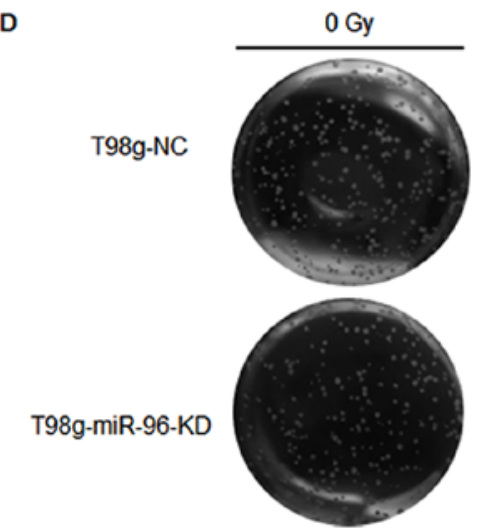

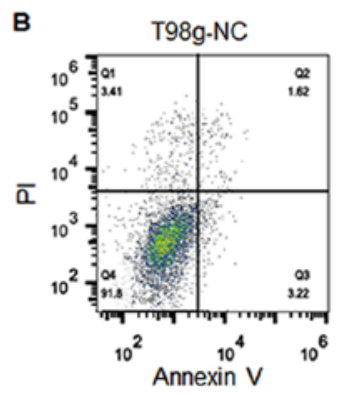

$6 \mathrm{~Gy}$

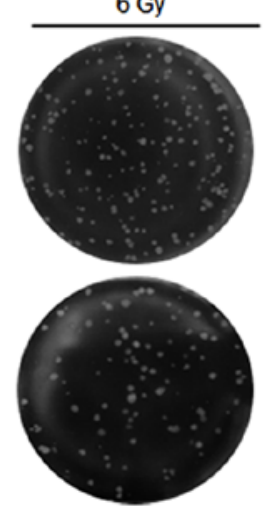

C
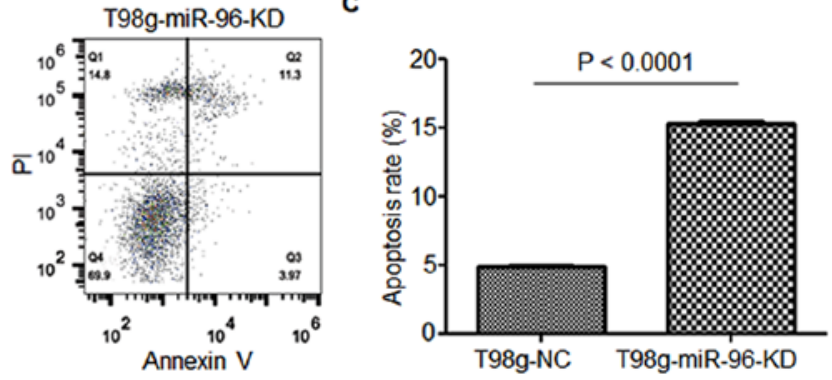

E

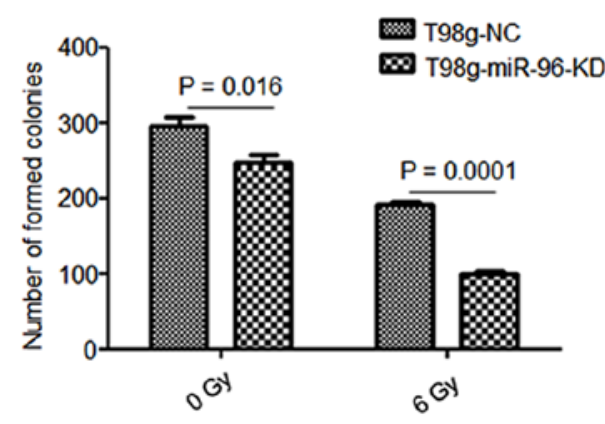

Figure 2. Knockdown of miR-96 in radioresistant T98G cells increases apoptosis and reduces proliferation following radiotherapy. (A) Relative miR-96 levels in T98g cells with or without miR-96 knockdown. (B) Representative plots and (C) quantification of flow cytometry analysis of cell apoptosis in T98g-NC and T98g-miR-96-KD cells treated with $6 \mathrm{~Gy}$ radiation. (D) Representative images and (E) quantification of clonogenic formation assay of T98g-NC and T98g-miR96-KD cells treated with 0 or 6 Gy radiation. All experiments were repeated three times. NC, negative control; KD, knockdown; PI, propidium iodide.

and analyzed using Cluster 3.0 software revealed that miR-96 expression was upregulated in GBM tissues compared to normal tissues (Fig. 1A). Therefore, the miR-96 expression was further analyzed in an array of GBM cell lines (U87-MG, U251-MG, A172 and T98g), which have been reported to have varying radiosensitivity (30). As illustrated in Fig. 1B, the T98g cells contained the highest levels of miR-96 expression, while the expression levels of miR-96 in U87-MG cells was significantly decreased, indicating that miR-96 levels might be associated with the radiosensitivity status of GBM cells.

Knockdown of miR-96 in radioresistant T98G cells increases apoptosis and reduces proliferation following radiotherapy. To investigate the function of miR-96 in GBM radiosensitivity, a stable miR-96-knockdown T98g cell line was constructed using lentivirus. As presented in Fig. 2A, miR-96 was efficiently silenced in miR-96-KD cells compared with the negative control infected cells (NC). Results from apoptosis assay for these cells following 6-Gy radiation treatment revealed that miR-96 silencing in T98g cells increased the \% of apoptotic cells compared with the control group (Fig. 2B and C). Furthermore, a clonogenic formation assay revealed that miR-96 knockdown reduced the clonogenic formation ability of the T98g cells following radiotherapy compared with the control group (Fig. 2D and E). Taken together, these results indicated that knockdown of miR-96 in radioresistant T98G cells increased the \% of apoptotic cells and reduced their clonogenic formation ability following radiotherapy.

Overexpression of miR-96 in radiosensitive U87-MG cells inhibits apoptosis and increases proliferation following radiotherapy. To further clarify the function of $\mathrm{miR}-96$ in GBM radiosensitivity, a stable miR-96-overexpressing (OE) U87-MG cell line was constructed using lentivirus. As presented in Fig. 3A, miR-96 was efficiently overexpressed in miR-96-OE U87-MG cells compared with negative control (NC). An apoptosis assay for these cells following 6-Gy treatment demonstrated that miR-96 overexpression in U87-MG cells reduced the \% of apoptotic cells compared with the control group (Fig. 3B and C). In addition, a clonogenic formation assay revealed that miR-96 overexpression increased the clonogenic formation ability of the U87-MG cells following radiotherapy compared with the control group (Fig. 3D and E). Altogether, these results indicated that overexpression of miR-96 in the radiosensitive U87-MG cells reduced the $\%$ of apoptotic cells and increased their clonogenic formation ability following radiotherapy.

Knockdown of miR-96 in radioresistant T98G cells inhibits $D N A$ repair following radiotherapy. The ability to repair DNA double-strand breaks (DSBs) induced by radiation is highly associated with radiotherapy. As a classic marker of DSBs, the induction of $\gamma \mathrm{H} 2 \mathrm{AX}$ nuclear foci was examined in the present study. T98g control and T98g miR-96-KD cells were irradiated ( 0 or $6 \mathrm{~Gy}$ ). Compared with the control cells, the number of $\gamma \mathrm{H} 2 \mathrm{AX}$ foci was significantly increased in the T98g miR-96-KD cells (Fig. 4A and B). These data suggest that T98g miR-96-KD cells are less able to perform DNA repair following irradiation. As an additional measure of the effects of miR-96 on radiation-induced DSBs, a comet assay was performed. For the comet assay, cells were treated with 0 or 6 Gy of radiation and collected at 0 and $3 \mathrm{~h}$. As illustrated 

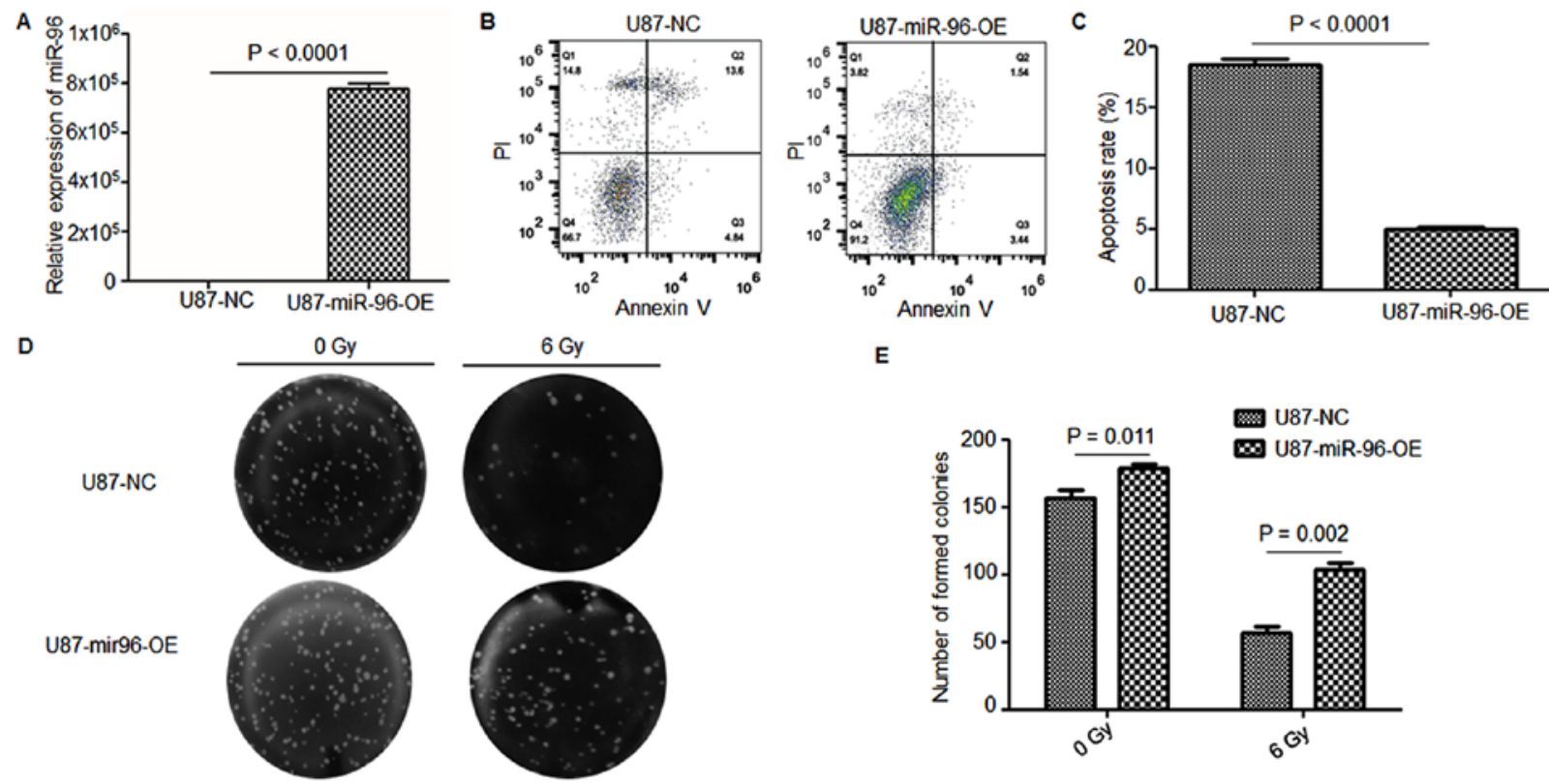

E

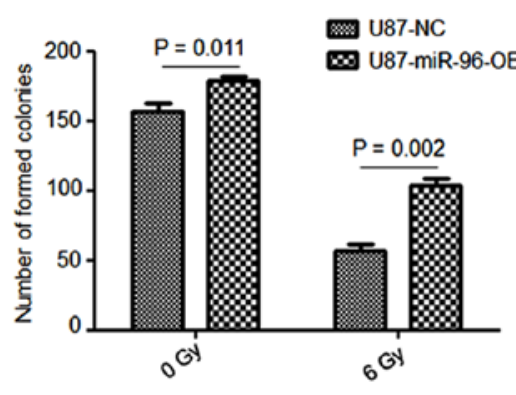

Figure 3. Overexpression of miR-96 in radiosensitive U87-MG cells inhibits apoptosis and enhances proliferation following radiotherapy. (A) Relative miR-96 levels in U87-MG cells with or without miR-96 overexpression. (B) Representative plots and (C) quantification of flow cytometry analysis of cell apoptosis in U87-NC and U87-miR-96-OE cells treated with 6 Gy radiation. (D) Representative images and (E) quantification of clonogenic formation assay of U87-NC and U87-miR-96-OE cells treated with 0 or $6 \mathrm{~Gy}$ radiation. All experiments were repeated three times. NC, negative control; OE, overexpression; PI, propidium iodide.

A

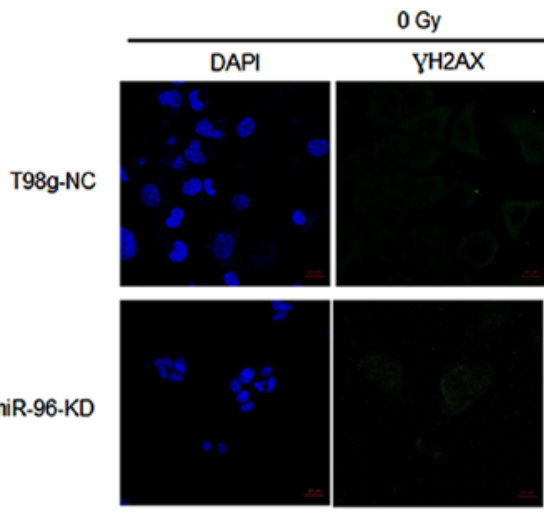

B
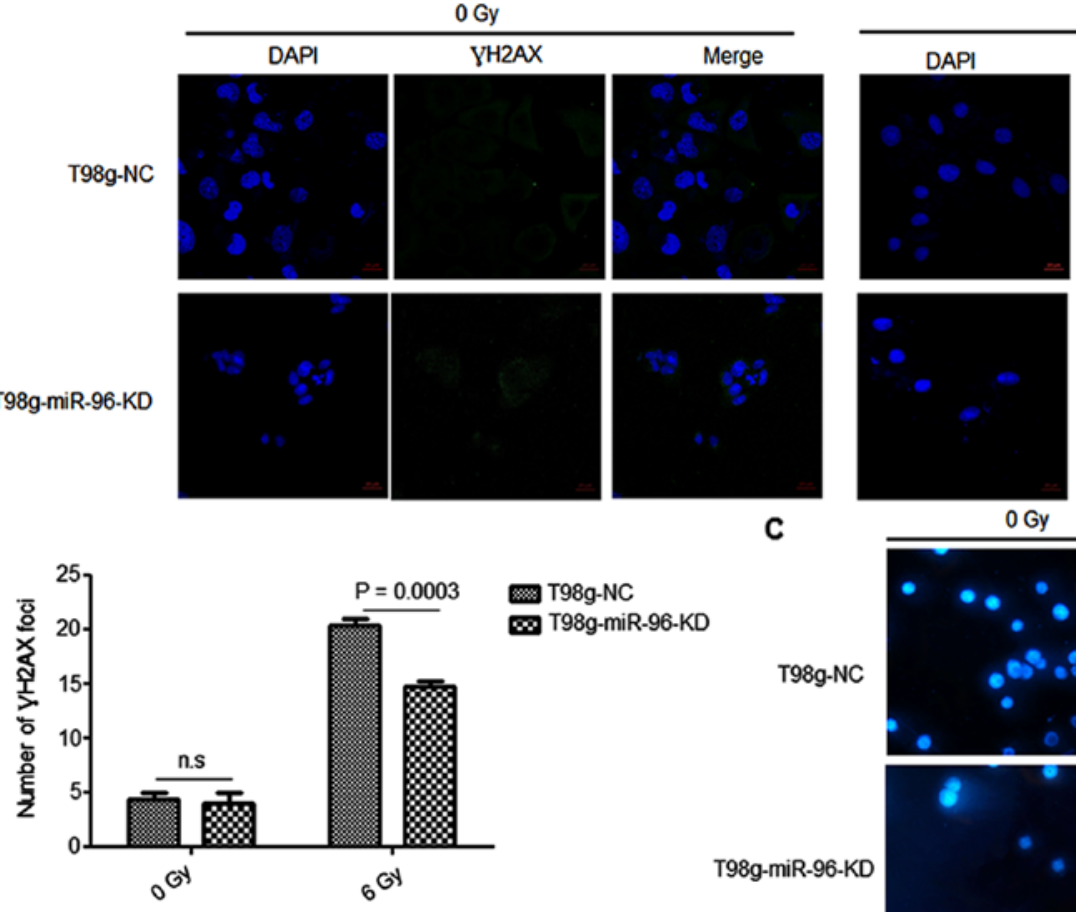

$6 G y$
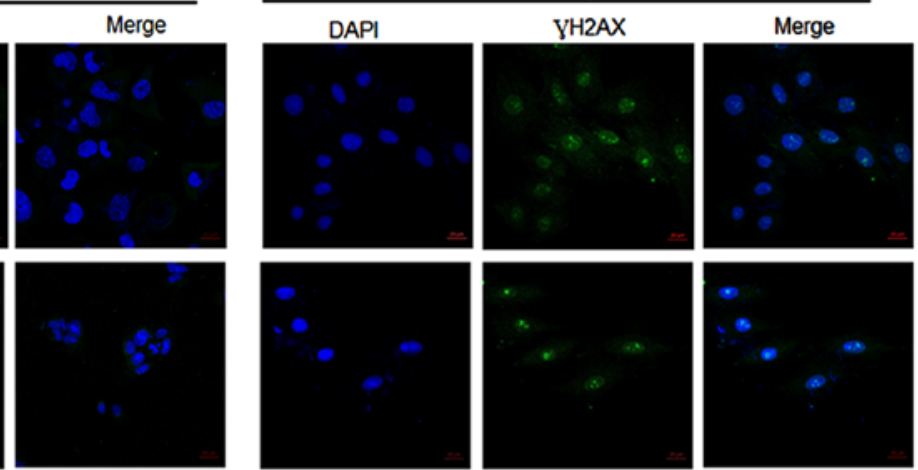

T98g-miR-96-KD

B
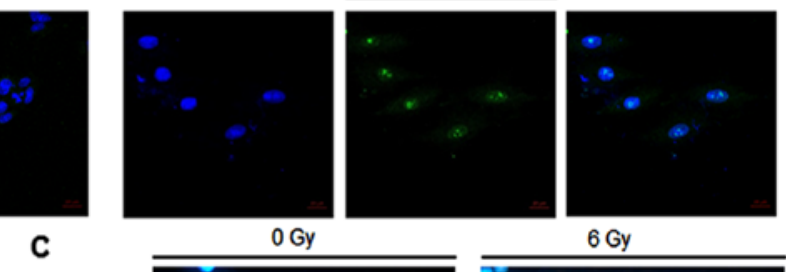

C
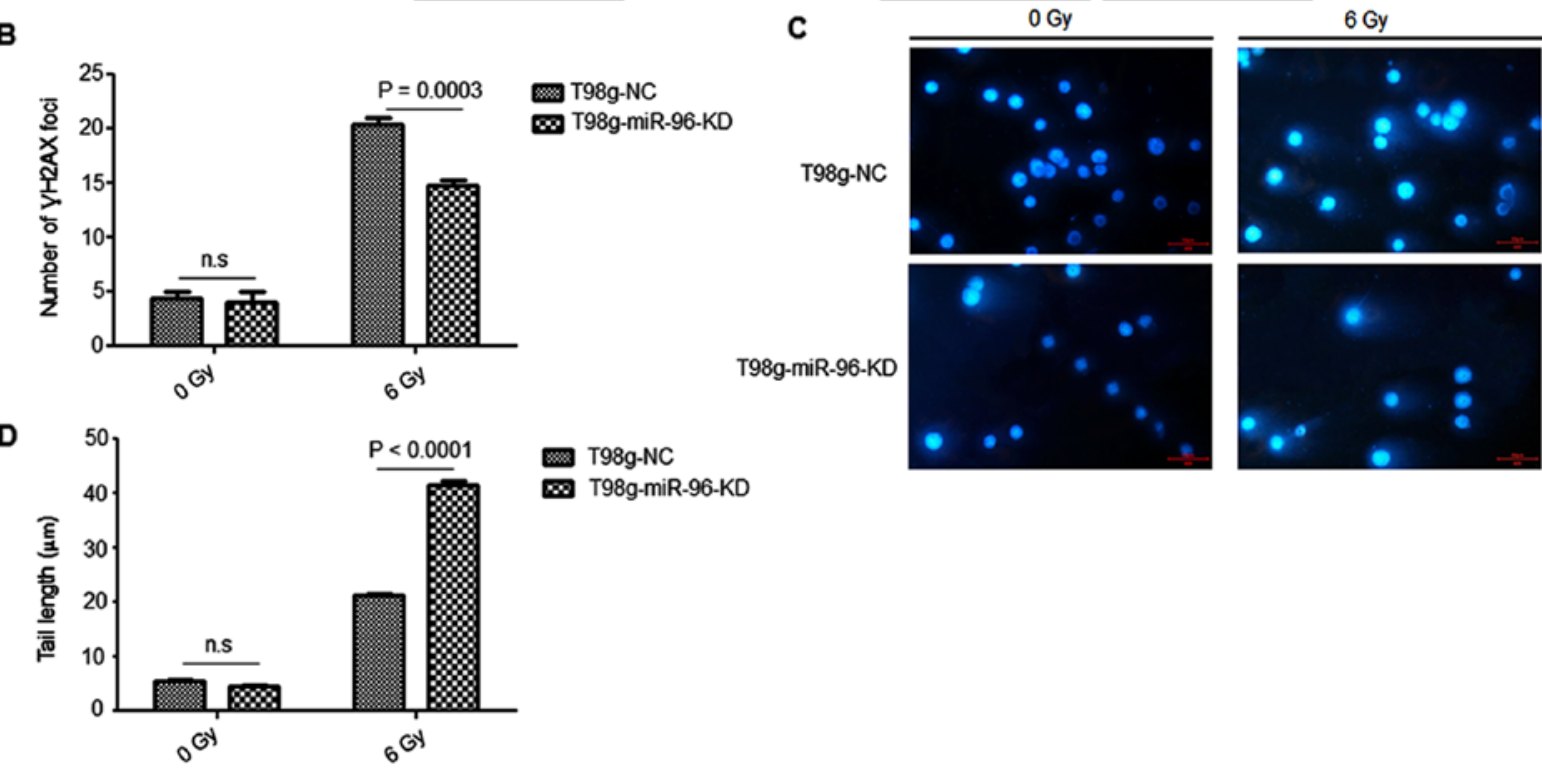

T98g-miR-96-KD

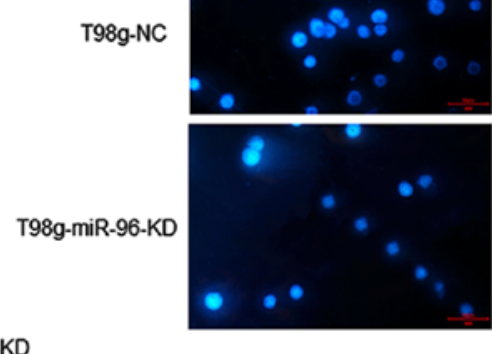

T98g-miR-96-KD

Figure 4. Knockdown of miR-96 in radioresistant T98G cells inhibits DNA repair following radiotherapy. (A) Representative images and (B) quantification of $\gamma \mathrm{H} 2 \mathrm{AX}$ immunostaining in T98g-NC and T98g-miR-96-KD cells treated with 0 or 6 Gy radiation. (C) Representative images and (D) quantification of comet assay in T98g-NC and T98g-miR-96-KD cells treated with 0 or 6 Gy radiation. All experiments were repeated three times. $\gamma \mathrm{H} 2 \mathrm{AX}$, phosphorylated-H2A histone family member X; NC, negative control; KD, knockdown; n.s., not significant. 
A $0 \mathrm{~Gy}$

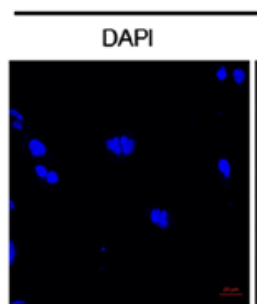

YH2AX
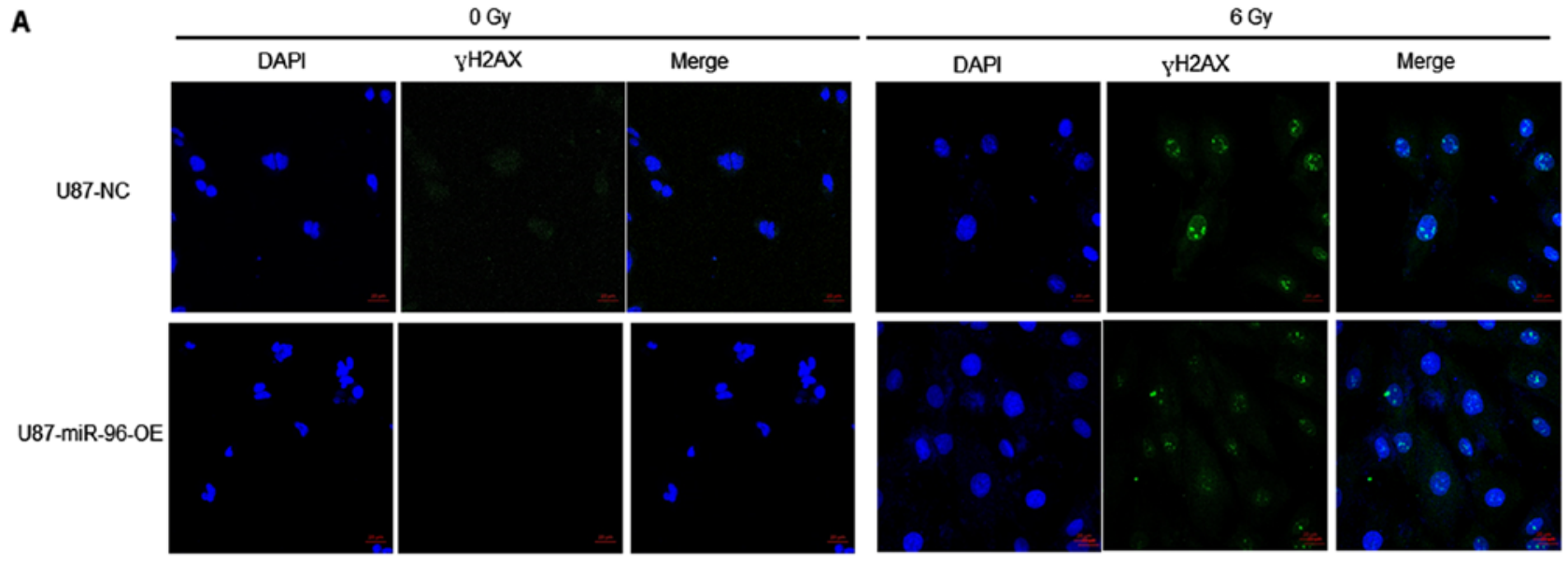

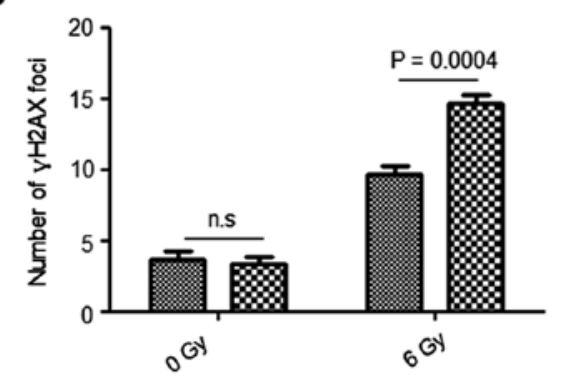

D

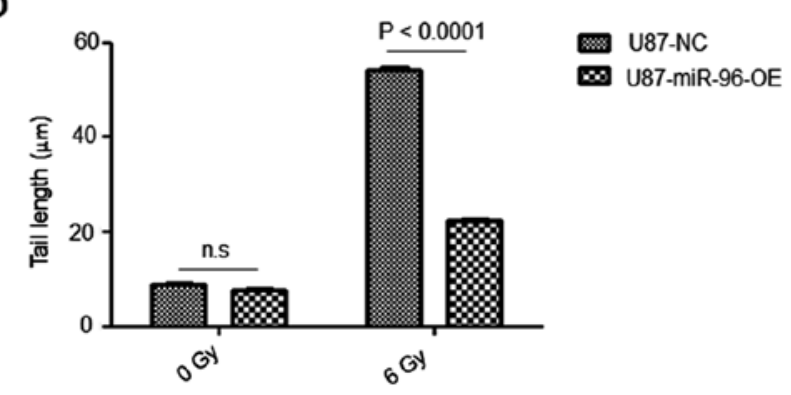
U87-miR-96-OE

C

0 Gy

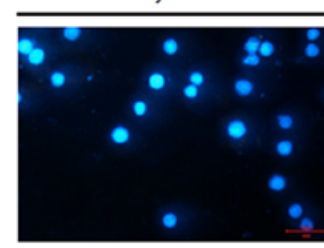

U87-NC

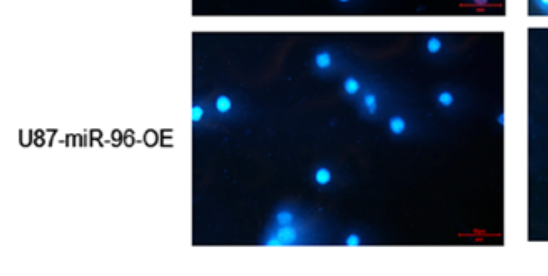

$6 \mathrm{~Gy}$

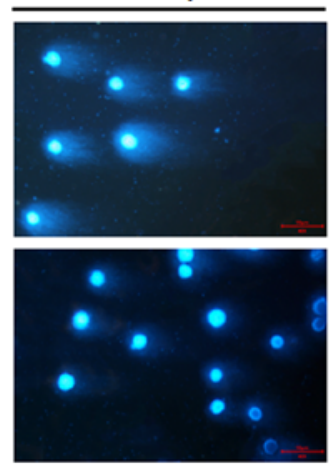

U87-miR-96-OE

(n)

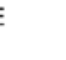

Figure 5. Overexpression of miR-96 in radiosensitive U87-MG cells enhances DNA repair following radiotherapy. (A) Representative images and (B) quantification of $\gamma \mathrm{H} 2 \mathrm{AX}$ immunostaining in U87-NC and U87-miR-96-OE cells treated with 0 or 6 Gy radiation. (C) Representative images and (D) quantification of comet assay in U87-NC and U87-miR-96-OE cells treated with 0 or 6 Gy radiation. All experiments were repeated three times. $\gamma \mathrm{H} 2 \mathrm{AX}$, phosphorylated-H2A histone family member $\mathrm{X}$; NC, negative control; OE, overexpression.

in Fig. 4C and D, the OTM was significantly increased in the T98g miR-96-KD cells compared with the control cells. Taken together, these data suggest that knockdown of miR-96 in the radioresistant $\mathrm{T} 98 \mathrm{G}$ cells reduced their DNA repair ability following radiotherapy.

Overexpression of miR-96 in radiosensitive U87-MG cells enhances DNA repair following radiotherapy. Next, the induction of $\gamma \mathrm{H} 2 \mathrm{AX}$ nuclear foci was examined in U87-miR-96-OE cells. The negative control and U87-miR-96-OE cells were irradiated ( 0 or $6 \mathrm{~Gy}$ ). Compared with the control cells, the number of $\gamma \mathrm{H} 2 \mathrm{AX}$ foci was significantly reduced in the U87-miR-96-OE cells (Fig. 5A and B). These data indicated that U87-miR-96-OE cells had an increased DNA repair ability following radiation. In addition, a comet assay was performed after the cells were treated with 0 or 6 Gy of radiation and collected at 0 and $3 \mathrm{~h}$. As presented in Fig. 5C and D, the OTM was significantly reduced in the U87-miR-96-OE cells compared with the controls cells. Taken together, these data suggest that overexpression of miR-96 in the radiosensitive
U87-MG cells enhanced their DNA repair ability following radiotherapy.

miR-96 suppresses the expression of PDCD4 in GMB cells. In order to clarify the molecular mechanisms of miR-96 in GBM radiosensitivity, the potential target genes of miR-96 were analyzed. As illustrated in Fig. 6A, the 3'UTR of the PDCD4 gene contains miR-96 binding sequences using miRanda software (33). A luciferase assay was performed in order to confirm that PDCD4 is a direct target of miR-96. The luciferase assay results revealed that miR-96 mimics significantly inhibited the luciferase activity of the reporter vector, but did not suppress the luciferase activity of a mutant vector, suggesting that miR-96 directly binds to the 3'UTR of the PDCD4 mRNA (Fig. 6B). Furthermore, the mRNA expression levels of PDCD4 were analyzed in U87-miR-96-OE cells. Compared with negative control cells, mRNA expression of PDCD4 was significantly reduced in U87-miR-96-OE cells (Fig. 6C). By contrast, mRNA expression of PDCD4 was significantly increased in T98g-miR-96-KD cells compared 
A

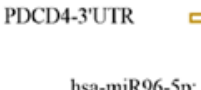

hsa-miR96-5p:

| | | | | |

PDCD4-3'UTR(1103-1136bp)-wt: 5'-GUGCUAAUUUAAACUGCCAAAUAUUGACUGCAGC-3' PDCD4-3'UTR(1103-1136bp)-mut: 5'-GUGCUAAUUUAAACCUUUCCAUAUUGACUGCAGC-3'
B
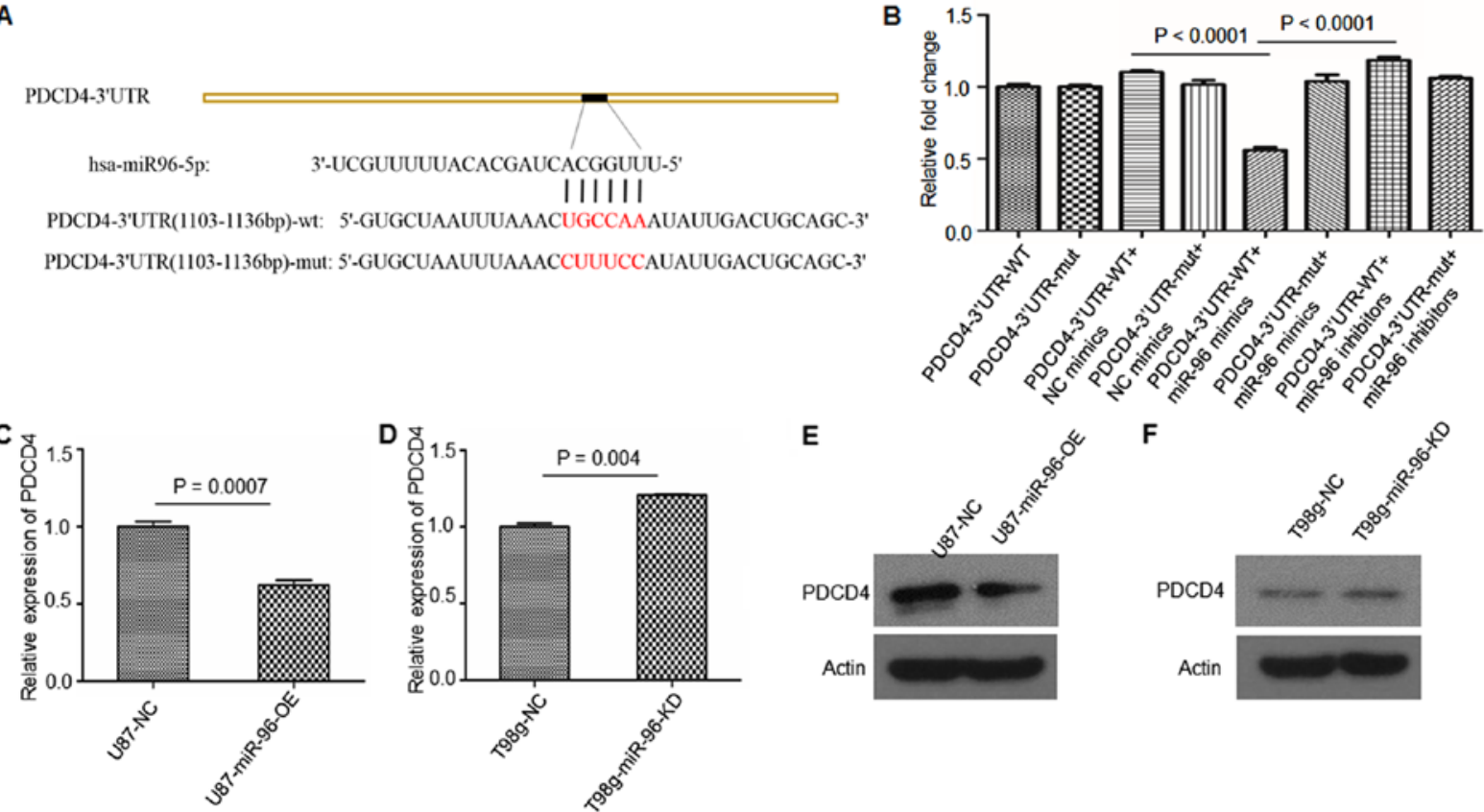

E

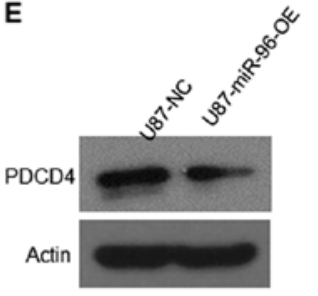

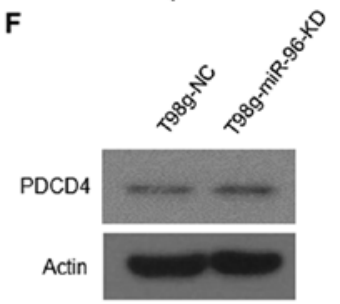

Figure 6. miR-96 suppresses the expression of PDCD4 in glioblastoma cells. (A) Schematic representation of the 3'UTR of the human PDCD4 gene and its predicted binding site for miR-96. Nucleotides in red font [PDCD4-3'UTR (1103-1136 bp)-mut] were mutated as a control for the luciferase assay. (B) Luciferase reporter assay for the miR-96 activity on the PDCD4 3'UTR. (C) Relative PDCD4 mRNA levels in U87-MG cells with or without miR-96 overexpression. (D) Relative PDCD4 mRNA levels in T98g cells with or without miR-96 knockdown. (E) Western blot analysis of PDCD4 protein levels in U87-MG cells with or without miR-96 overexpression. (F) Western blot analysis of PDCD4 protein levels in T98g cells with or without miR-96 knockdown. PDCD4, programmed cell death protein 4; UTR, untranslated region; wt, wild-type; mut, mutant; NC, negative control; OE, overexpression; KD, knockdown.

A

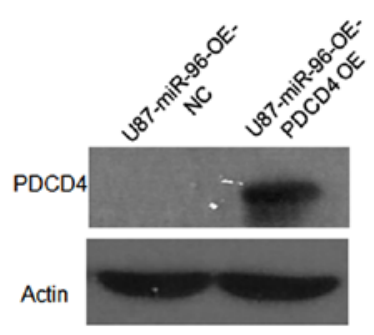

D

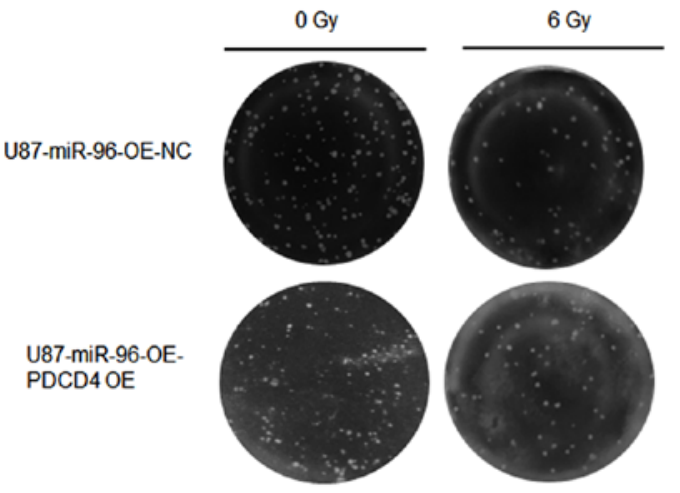

B
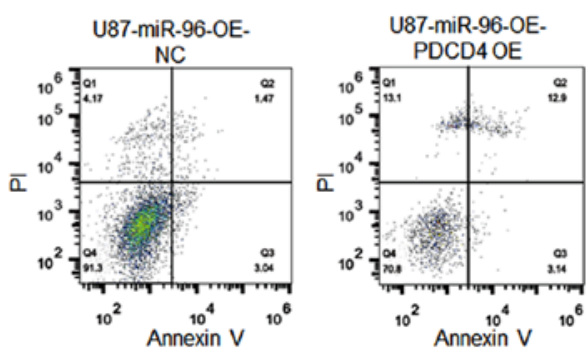

E

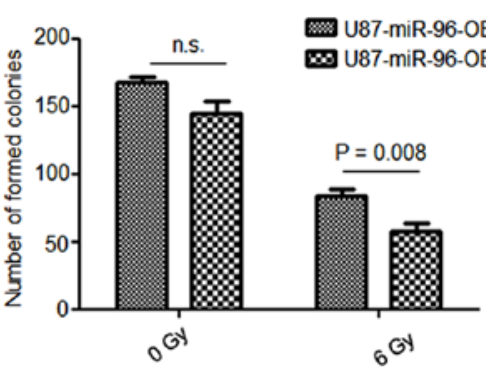

Figure 7. PDCD4-overexpressing U87-miR-96-OE cells regain radiosensitivity. (A) Western blot analysis of PDCD4 protein levels in U87-miR-96-OE cells with or without PDCD4 overexpression. (B) Representative plots and (C) quantification of flow cytometry analysis of cell apoptosis in U87-miR-96-OE-NC and U87-miR-96-OE-PDCD4 OE cells treated with 6 Gy radiation. (D) Representative images and (E) quantification of clonogenic formation assay of U87-miR-96-OE-NC and U87-miR-96-OE-PDCD4 OE cells treated with 6 Gy radiation. All experiments were repeated three times. PDCD4, programmed cell death protein 4; OE, overexpression; NC, negative control; PI, propidium iodide.

with the negative control cells (Fig. 6D). Results from western blot analysis confirmed these results at the protein level (Fig. 6E and F). These data demonstrated that miR-96 suppressed the expression of PDCD4 in GMB cells.
PDCD4-overexpressing U87-MG cells regain radiosensitivity. To discover whether miR-96-mediated radioresistance occurred through targeting PDCD4, a stable PDCD4overexpressing cell lines was constructed in U87-miR-96-OE 
A

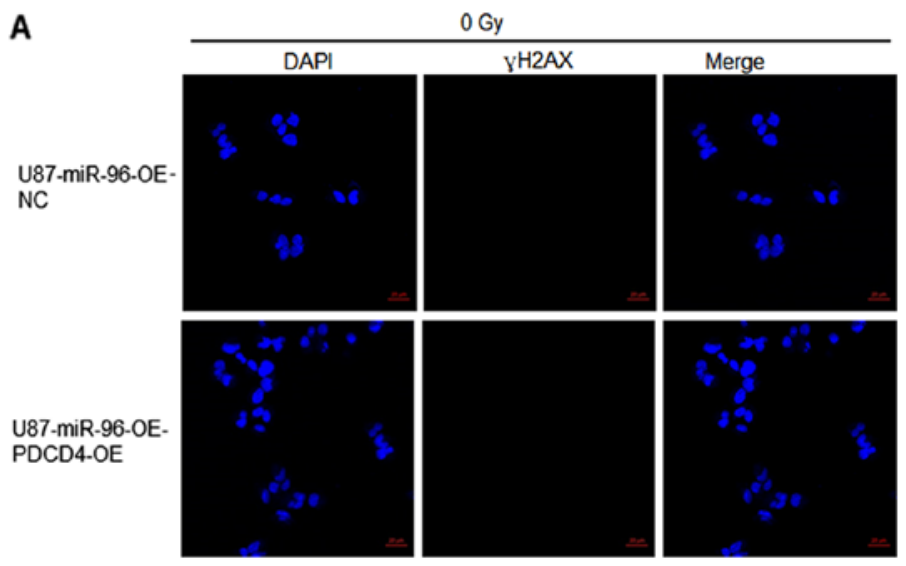

$0 \mathrm{~Gy}$

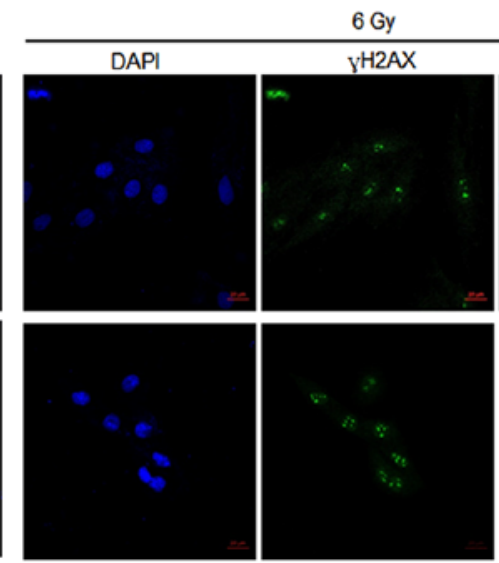

Merge

B

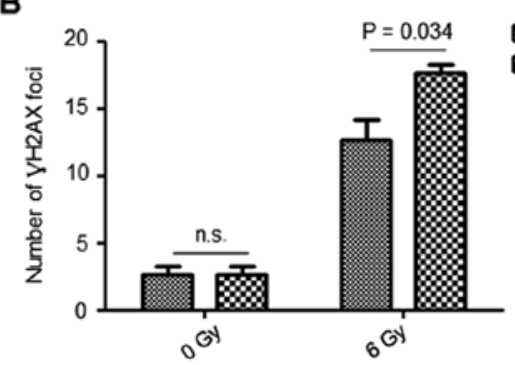

C

0 Gy

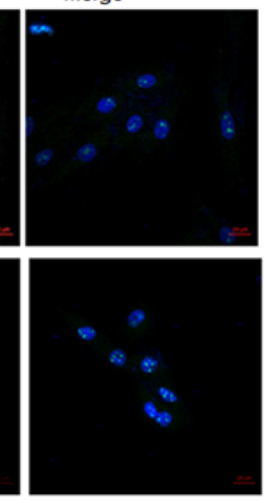

$6 \mathrm{~Gy}$

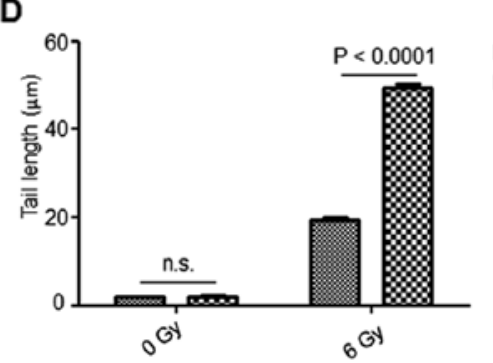

U BO U87-miR-96-OE-PDCD4 OE
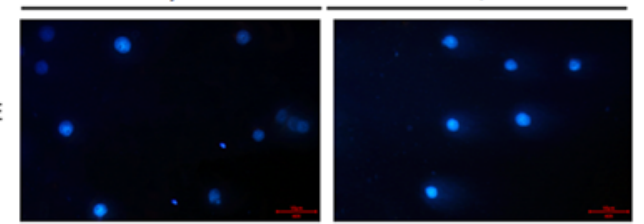

U87-miR-96-OE -NC
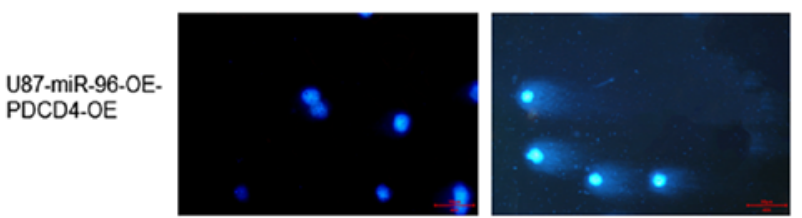

U $087-$ miR-96-OE-PDCD4 OE

Figure 8. Overexpression of PDCD4 in U87-miR-96-OE cells inhibits DNA repair following radiotherapy. (A) Representative images and (B) quantification of $\gamma \mathrm{H} 2 \mathrm{AX}$ immunostaining in U87-miR-96-OE-NC and U87-miR-96-OE-PDCD4 OE cells treated with 0 or 6 Gy radiation. (C) Representative images and (D) quantification of comet assay in U87-miR-96-OE-NC and U87-miR-96-OE-PDCD4 OE cells treated with 0 or 6 Gy radiation. All experiments were repeated three times. PDCD4, programmed cell death protein 4; OE, overexpression; $\gamma \mathrm{H} 2 \mathrm{AX}$, phosphorylated-H2A histone family member X; NC, negative control.

cells. As illustrated in Fig. 7A, PDCD4 was efficiently overexpressed in U87-miR-96-OE cells compared with negative control. An apoptosis assay for these cells following 6-Gy treatment demonstrated that PDCD4 overexpression in U87-miR-96-OE cells increased the $\%$ of apoptotic cells compared with the control group (Fig. 7B and C). Furthermore, a clonogenic formation assay revealed that PDCD4 overexpression in U87-miR-96-OE cells reduced their clonogenic formation ability following radiotherapy (Fig. 7D and E).

As far as DNA repair is concerned, the number of $\gamma \mathrm{H} 2 \mathrm{AX}$ foci was significantly elevated in the PDCD4-overexpressing U87-miR-96-OE cells compared with the control group (Fig. 8A and B). These data indicated that the PDCD4overexpressing U87-miR-96-OE cells were less able to perform DNA repair. For the comet assay, cells were treated with 0 or $6 \mathrm{~Gy}$ of radiation and collected at 0 and $3 \mathrm{~h}$. As presented in Fig. 8C and D, the OTM was significantly increased in the PDCD4-overexpressing U87-miR-96-OE cells compared with the control cells. Altogether, these results indicated that PDCD4 overexpression reversed the effects of miR-96 on the radiosensitivity of U87-MG cells.

\section{Discussion}

The current GBM treatment standards include maximal resection followed by radiotherapy with concomitant and adjuvant therapies (32). Despite these aggressive therapeutic regimens, the majority of patients suffer recurrence due to molecular heterogeneity of GBM (33). A number of genes associated with radiotherapy response have been investigated, including isocitrate dehydrogenase mutations, 1p19q deletion, O-6-methylguanine-DNA methyltransferase promoter methylation, and epidermal growth factor receptor variant III amplification (34-37). Besides these mechanisms, resistance to radiotherapy involves cancer stem cells (38). In the present study, miR-96 was demonstrated to be significantly upregulated in radioresistant GBM cells, indicating that miR-96 might be a novel biomarker for radiotherapy response in GBM. In addition to miR-96, we previously reported that inhibitor of DNA binding 1 affects the efficacy of radiotherapy in GBM (39). The underlying molecular mechanisms of radioresistance are very complex and need further investigation.

miR-96 has multiple functions in tumor progression. Upregulation of miR-96 reduces the susceptibility of esophageal cancer cells to chemotherapy or radiotherapy (19). 
Consistently, the present results revealed that overexpression of miR-96 in radiosensitive GBM cells reduced radiosensitivity. By contrast, knockdown of miR-96 in radioresistant GBM cells enhanced their radiosensitivity. Thus, upregulated miR-96 promotes radioresistance in glioblastoma cells, and targeting miR-96 might be a novel strategy in GBM treatment.

PDCD4 is a potential tumor suppressor gene in GBM by mediating apoptosis, which may in turn result in the resistance of GBM cells against chemotherapy or radiation (40). Downregulation of PDCD4 is associated with a poor prognosis. miRNAs, such as miR-21 and miR-183, target PDCD4 $(6,30,41)$. In this study, the importance of miR-96 was revealed by microarray analysis of clinical samples, where miR-96 was demonstrated to be upregulated in GBM cases compared with normal tissues (Fig. 1). However, the potential cooperation between miR-96 and miR-21 remains unclear and needs further investigation. The present study was the first study to demonstrate that upregulated miR-96 promotes radioresistance in glioblastoma cells via targeting PDCD4. All these findings suggest that miR-96 might be a potential therapeutic target for GBM.

\section{Acknowledgements}

Not applicable.

\section{Funding}

This study was supported by the National Science Foundation of China (grant nos. 81502151 and 81502025), and the Natural Science Foundation of Shandong Province (grant nos. ZR2015HQ008 and ZR2015PH011).

\section{Availability of data and materials}

The analyzed datasets generated during the study are available from the corresponding author on reasonable request.

\section{Authors' contributions}

LZ and WY conceived and designed the study. PG and YY performed the experiments and wrote the manuscript. ZT provided the mutants. YL and YQ were involved in drafting and critically revising the manuscript. All authors have read and approved the manuscript.

\section{Ethics approval and consent to participate}

Not applicable.

\section{Consent for publication}

Not applicable.

\section{Competing interests}

The authors declare that they have no competing interests.

\section{References}

1. Wen PY and Kesari S: Malignant gliomas in adults. N Engl J Med 359: 492-507, 2008.
2. Stupp R, Hegi ME, Mason WP, van den Bent MJ, Taphoorn MJ, Janzer RC, Ludwin SK, Allgeier A, Fisher B, Belanger K, et al; European Organisation for Research and Treatment of Cancer Brain Tumour and Radiation Oncology Groups; National Cancer Institute of Canada Clinical Trials Group: Effects of radiotherapy with concomitant and adjuvant temozolomide versus radiotherapy alone on survival in glioblastoma in a randomised phase III study: 5-year analysis of the EORTC-NCIC trial. Lancet Oncol 10: 459-466, 2009.

3. Stupp R, Mason WP, van den Bent MJ, Weller M, Fisher B, Taphoorn MJ, Belanger K, Brandes AA, Marosi C, Bogdahn U, et al; European Organisation for Research and Treatment of Cancer Brain Tumor and Radiotherapy Groups; National Cancer Institute of Canada Clinical Trials Group: Radiotherapy plus concomitant and adjuvant temozolomide for glioblastoma. N Engl J Med 352: 987-996, 2005.

4. Kirkpatrick JP, Laack NN, Shih HA and Gondi V: Management of GBM: A problem of local recurrence. J Neurooncol 134: 487-493, 2017.

5. Fidoamore A, Cristiano L, Antonosante A, d'Angelo M, Di Giacomo E, Astarita C, Giordano A, Ippoliti R, Benedetti E and Cimini A: Glioblastoma stem cells microenvironment: The paracrine roles of the niche in drug and radioresistance. Stem Cells Int 2016: 6809105, 2016.

6. Chen Y, Liu W, Chao T, Zhang Y, Yan X, Gong Y, Qiang B, Yuan J, Sun M and Peng X: MicroRNA-21 down-regulates the expression of tumor suppressor PDCD4 in human glioblastoma cell T98G. Cancer Lett 272: 197-205, 2008

7. Papagiannakopoulos T, Shapiro A and Kosik KS: MicroRNA-21 targets a network of key tumor-suppressive pathways in glioblastoma cells. Cancer Res 68: 8164-8172, 2008.

8. Hu J, Sun T, Wang H, Chen Z, Wang S, Yuan L, Liu T, Li HR, Wang P, Feng Y, et al: miR-215 Is induced post-transcriptionally via HIF-Drosha complex and mediates glioma-initiating cell adaptation to hypoxia by targeting KDM1B. Cancer Cell 29: 49-60, 2016.

9. Shi Y, Chen C, Zhang X, Liu Q, Xu JL, Zhang HR, Yao XH, Jiang T, He ZC, Ren Y, et al: Primate-specific miR-663 functions as a tumor suppressor by targeting PIK3CD and predicts the prognosis of human glioblastoma. Clin Cancer Res 20: 1803-1813, 2014.

10. Hong Y, Liang H, Uzair-Ur-Rehman, Wang Y, Zhang W, Zhou Y, Chen S, Yu M, Cui S, Liu M, et al: miR-96 promotes cell proliferation, migration and invasion by targeting PTPN9 in breast cancer. Sci Rep 6: 37421, 2016.

11. Xu L, Zhong J, Guo B, Zhu Q, Liang H, Wen N, Yun W and Zhang L: miR-96 promotes the growth of prostate carcinoma cells by suppressing MTSS1. Tumour Biol 37: 12023-12032, 2016.

12. Wang TH, Yeh CT, Ho JY, Ng KF and Chen TC: OncomiR miR-96 and miR-182 promote cell proliferation and invasion through targeting ephrinA5 in hepatocellular carcinoma. Mol Carcinog 55: 366-375, 2016.

13. Ma Y, Yang HZ, Dong BJ, Zou HB, Zhou Y, Kong XM and Huang YR: Biphasic regulation of autophagy by miR-96 in prostate cancer cells under hypoxia. Oncotarget 5: 9169-9182, 2014.

14. Yu S, Lu Z, Liu C, Meng Y, Ma Y, Zhao W, Liu J, Yu J and Chen J: miRNA-96 suppresses KRAS and functions as a tumor suppressor gene in pancreatic cancer. Cancer Res 70: 6015-6025, 2010.

15. Tanaka M,Suzuki HI, Shibahara J, Kunita A,Isagawa T, Yoshimi A, Kurokawa M, Miyazono K, Aburatani H, Ishikawa S, et al: EVI1 oncogene promotes KRAS pathway through suppression of microRNA-96 in pancreatic carcinogenesis. Oncogene 33: 2454-2463, 2014.

16. Ress AL, Stiegelbauer V, Winter E, Schwarzenbacher D, Kiesslich T, Lax S, Jahn S, Deutsch A, Bauernhofer T, Ling H, et al: miR-96-5p influences cellular growth and is associated with poor survival in colorectal cancer patients. Mol Carcinog 54: 1442-1450, 2015.

17. Leung WK, He M, Chan AW, Law PT and Wong N: Wnt/ $\beta$-Catenin activates miR-183/96/182 expression in hepatocellular carcinoma that promotes cell invasion. Cancer Lett 362: 97-105, 2015.

18. Wu L, Pu X, Wang Q, Cao J, Xu F, Xu LI and Li K: miR-96 induces cisplatin chemoresistance in non-small cell lung cancer cells by downregulating SAMD9. Oncol Lett 11: 945-952, 2016.

19. Xia H, Chen S, Chen K, Huang H and Ma H: miR-96 promotes proliferation and chemo- or radioresistance by down-regulating RECK in esophageal cancer. Biomed Pharmacother 68: 951-958, 2014. 
20. Liao J, Liu R, Shi YJ, Yin LH and Pu YP: Exosome-shuttling microRNA-21 promotes cell migration and invasion-targeting PDCD4 in esophageal cancer. Int J Oncol 48: 2567-2579, 2016.

21. Zhang X, Gee H, Rose B, Lee CS, Clark J, Elliott M, Gamble JR, Cairns MJ, Harris A, Khoury S, et al: Regulation of the tumour suppressor PDCD4 by miR-499 and miR-21 in oropharyngeal cancers. BMC Cancer 16: 86, 2016.

22. Hwang SK, Baker AR, Young MR and Colburn NH: Tumor suppressor PDCD4 inhibits NF- $\mathrm{BB}$-dependent transcription in human glioblastoma cells by direct interaction with p65. Carcinogenesis 35: 1469-1480, 2014.

23. Wang L, Zhao M, Guo C, Wang G, Zhu F, Wang J, Wang X, Wang $\mathrm{Q}$, Zhao W, Shi Y, et al: PDCD4 deficiency aggravated colitis and colitis-associated colorectal cancer via promoting IL-6/STAT3 pathway in mice. Inflamm Bowel Dis 22: 1107-1118, 2016.

24. Zhen Y, Li D, Li W, Yao W, Wu A, Huang J, Gu H, Huang Y, Wang Y, Wu J, et al: Reduced PDCD4 expression promotes sell growth through PI3K/Akt signaling in non-small cell lung cancer. Oncol Res 23: 61-68, 2016.

25. Chen Z, Yuan YC, Wang Y, Liu Z, Chan HJ and Chen S: Downregulation of programmed cell death 4 (PDCD4) is associated with aromatase inhibitor resistance and a poor prognosis in estrogen receptor-positive breast cancer. Breast Cancer Res Treat 152: 29-39, 2015.

26. Supiot S, Gouraud W, Campion L, Jezéquel P, Buecher B, Charrier J, Heymann MF, Mahé MA, Rio E and Chérel M: Early dynamic transcriptomic changes during preoperative radiotherapy in patients with rectal cancer: A feasibility study. World J Gastroenterol 19: 3249-3254, 2013.

27. Bredel M, Scholtens DM, Harsh GR, Bredel C, Chandler JP, Renfrow JJ, Yadav AK, Vogel H, Scheck AC, Tibshirani R, et al: A network model of a cooperative genetic landscape in brain tumors. JAMA 302: 261-275, 2009.

28. Gao F, Wang X, Zhu F, Wang Q, Zhang X, Guo C, Zhou C, Ma C, Sun W, Zhang Y, et al: PDCD4 gene silencing in gliomas is associated with $5^{\prime} \mathrm{CpG}$ island methylation and unfavourable prognosis. J Cell Mol Med 13: 4257-4267, 2009.

29. Xiao J, Pan Y, Li XH, Yang XY, Feng YL, Tan HH, Jiang L, Feng J and Yu XY: Cardiac progenitor cell-derived exosomes prevent cardiomyocytes apoptosis through exosomal miR-21 by targeting PDCD4. Cell Death Dis 7: e2277, 2016.
30. Jiang LP, He CY and Zhu ZT: Role of microRNA-21 in radiosensitivity in non-small cell lung cancer cells by targeting PDCD4 gene. Oncotarget 8: 23675-23689, 2017.

31. Allen M, Bjerke M, Edlund H, Nelander S and Westermark B: Origin of the U87MG glioma cell line: Good news and bad news. Sci Transl Med 8: 354re3, 2016.

32. Lee DH, Ryu HW, Won HR and Kwon SH: Advances in epigenetic glioblastoma therapy. Oncotarget 8: 18577-18589, 2017.

33. Shen Y, Wang Y, Sheng K, Fei X, Guo Q, Larner J, Kong X, Qiu Y and Mi J: Serine/threonine protein phosphatase 6 modulates the radiation sensitivity of glioblastoma. Cell Death Dis 2: e241, 2011.

34. Jalbert LE, Elkhaled A, Phillips JJ, Neill E, Williams A, Crane JC, Olson MP, Molinaro AM, Berger MS, Kurhanewicz J, et al: Metabolic profiling of IDH mutation and malignant progression in infiltrating glioma. Sci Rep 7: 44792, 2017.

35. Wang J, Su HK, Zhao HF, Chen ZP and To SS: Progress in the application of molecular biomarkers in gliomas. Biochem Biophys Res Commun 465: 1-4, 2015.

36. Binabaj MM, Bahrami A, ShahidSales S, Joodi M, Joudi Mashhad M, Hassanian SM, Anvari K and Avan A: The prognostic value of MGMT promoter methylation in glioblastoma: A meta-analysis of clinical trials. J Cell Physiol 233: 378-386, 2018.

37. Figueroa JM, Skog J, Akers J, Li H, Komotar R, Jensen R, Ringel F, Yang I, Kalkanis S, Thompson R, et al: Detection of wild-type EGFR amplification and EGFRvIII mutation in CSF-derived extracellular vesicles of glioblastoma patients. Neuro Oncol 19: 1494-1502, 2017.

38. Bao S, Wu Q, McLendon RE, Hao Y, Shi Q, Hjelmeland AB, Dewhirst MW, Bigner DD and Rich JN: Glioma stem cells promote radioresistance by preferential activation of the DNA damage response. Nature 444: 756-760, 2006.

39. Guo Q, Guo P, Mao Q, Lan J, Lin Y, Jiang J and Qiu Y: ID1 affects the efficacy of radiotherapy in glioblastoma through inhibition of DNA repair pathways. Med Oncol 30: 325, 2013.

40. Costa PM, Cardoso AL, Nóbrega C, Pereira de Almeida LF Bruce JN, Canoll P and Pedroso de Lima MC: MicroRNA-21 silencing enhances the cytotoxic effect of the antiangiogenic drug sunitinib in glioblastoma. Hum Mol Genet 22: 904-918, 2013.

41. Cheng Y, Xiang G, Meng Y and Dong R: MiRNA-183-5p promotes cell proliferation and inhibits apoptosis in human breast cancer by targeting the PDCD4. Reprod Biol 16: 225-233, 2016. 